Kukleta, M. Memory components of shock escape reaction in rat. Physiology \& Behavior, 1968, 3, 773-776.

Krech, D., Rosenzweig, M. R., \& Bennett, E. L. Relations between brain chemistry and problem solving among rats raised in enriched and impoverished environments. Journal of Comparative \& Physiological Psychology, 1962, 55, 801-807.

Manosevitz, M. Early environmental enrichment and mouse behavior. Journal of Comparative \& Physiological Psychology, $1970,71,459-466$

Maatsch, J. L. Learning and fixation after a single shock trial. Journal of Comparative \& Physiological Psychology, 1959, 52 , 408-410.

Misanin, J. R., Haigh, J. M., Hinderliter, C. F., \& Nagy, Z. M Analysis of response competition in discriminated and non-discriminated escape training of neonatal rats. Journal of Comparative \& Physiological Psychology, 1973, 85, 570-580.

Misanin, J. R., Nagy, Z. M., Keiser, E. F., \& Bowen, W. Emergence of long-term memory in the neonatal rat. Journal of Comparative \& Physiological Psychology, 1971, 77, 188-199.

Misanin, J. R., Nagy, Z. M., \& Weiss, E. M. Escape behavior in neonatal rats. Psychonomic Science, 1970, 18, 191-192.

Misanin, J. R., Rose, S. J., \& Hinderliter, C. F. Escape behavior in neonatal rats: Methodological and psychometric considerations. Behavior Research Methods \& Instrumentation, 1971, 3, 253-254.

Ottinger, D. R., \& Tanabe, G. Maternal food restriction: Effects on offspring behavior and development. Developmental Psychobiology, 197, 6, 177-186.

Slob, A. K., Snow, C. E., \& Mathot, E. N. Absence of behavioral deficits following neonatal undernutrition in the rat. Developmental Psychobiology, 1973, 6, 177-186.

(R eceived for publication June 6, 1974.)

\title{
Word length and exposure time effects on the recognition of bilaterally presented words*
}

\author{
KATHLEEN M. GILL and WALTER F. McKEEVER \\ Bowling Green State University, Bowling Green, Ohio 43403
}

\begin{abstract}
Word length (two, three, four, and five letters) and exposure time (25, 50, and $100 \mathrm{msec})$ effects on visual half-field recognition performances were studied in a bilateral word presentation paradigm. Significant right-field recognition superiority (RFRS) obtained for all length-exposure time conditions except that for two-letter words exposed for $100 \mathrm{msec}$. RFRS was significantly greater for each of the two longer word lengths than for the two shorter lengths and for the 25-msec exposures than for the 50or 100-msec exposures. The magnitude of RFRS was substantially correlated with a "perceptual difficulty" measure (the ratio of the number of milliseconds available for viewing to the number of letters to be viewed). Results were seen as compatible with a hemispheric asymmetry hypothesis and a differential half-fields masking susceptibility mechanism.
\end{abstract}

Research on lateral visual half-field (VHF) recognition efficiency differences for letter and word stimuli has established that (1) unilateral stimulus presentation yields a right visual half-field (RVF) recognition superiority (Mishkin \& Forgays, 1952; Heron, 1957; Bryden, 1966; McKeever, 1971; and others); (2) bilateral presentation, with fixation controlled, yields a RVF recognition superiority of greater magnitude than obtained in unilateral presentation (McKeever, 1971; Sperry \& Teng, 1973; Olson, 1973); and (3) RVF superiority is not due to order of report bias (McKeever, 1971).

*Supported by Research Grant NS10214-02 from the National Institute of Neurological Diseases and Stroke, National Institutes of Health, to the second author.
Prominent among the factors whose effects might be expected to be well established are word length and exposure durations. Surprisingly, only one experiment has systematically varied word length in lateralized presentation (Bouma, 1973) and no systematic study of the effects of exposure time has been reported for lateralized words. ${ }^{1}$

Within the lateral dominance model of half-field recognition efficiency differences it has been suggested (McKeever \& Huling, 1971; Hines, 1974) that the need to transfer left visual field (LVF) stimulation from the right to the left cerebral hemisphere, in order to allow vocal report of that stimulation, might result in more extensive LVF information loss for longer words and for briefer exposures. Such stimulus trace degradation in 
transcallosal transfer should act to increase RVF superiority for longer words and shorter exposures. This hypothesis was examined within the bilateral word presentation paradigm. The factorial experiment utilized four word lengths (two, three, four, and five letters) and three exposure times $(25,50$, and $100 \mathrm{meec})$.

\section{METHOD}

\section{Subjects}

Ss were 144 right-handed undergraduates. They were randomly assigned, in equal numbers, to the 12 unique length-exposure time conditions.

\section{Stimuli}

Stimuli consisted of bilateral words, typed (elite, 10 point) in capital letters and having one typewriter space between letters. Four series of 24 cards were prepared, one series for each word length. In each series, each of the 24 words appeared once on each side of the center. Word pairings were randomly determined and roughly equated for initial letter across word lengths. The near point of each word to fixation corresponded to $1.25 \mathrm{deg}$ of horizontal visual angle. Two-, three-, four-, and five-letter words subtended $0.99,1.65,2.31$, and $2.97 \mathrm{deg}$, respectively. Vertical visual angle of all words was $0.5 \mathrm{deg}$. All words were equated for frequency of occurrence in print according to the Thorndike-Lorge tables (1944), all being among the most frequently occurring ("AA") words.

In addition to the word pairs, each card also contained a single arabic number from 2 to 9 at the point corresponding to the preexposure fixation point. The preexposure field contained only a small black circle, designating the fixation point at midfield. This circle was just large enough to encompass the fixation number of each card as it was briefly exposed, and accuracy in perceiving the number required precise fixation. The luminence of the preexposure and exposure fields, measured at the eyepiece with a Pritchard photometer, were 4.5 and $4.0 \mathrm{fL}$, respectively.

\section{Apparatus}

Apparatus, instructions, procedure, and scoring were identical to those reported previously for bilateral stimuli (McKeever, 1971).

\section{RESULTS}

Table 1 gives mean recognition scores for the length, exposure, and VHF factors of the experiment, as well as mean VHF scores across all lengths and all exposures. A three-way analysis of variance, with repeated measures on the VHF factor, revealed significant effects of word length $(\mathrm{F}=9.11, \mathrm{df}=3 / 132, \mathrm{p}<.001)$, of exposure time $(\mathrm{F}=33.23, \mathrm{df}=2 / 132, \mathrm{p}<.001)$ and of VHF $(\mathrm{F}=196.13, \mathrm{df}=1 / 132, \mathrm{p}<.001)$. In addition, there was a significant interaction of Word Length by VHF $(\mathrm{F}=4.95, \mathrm{df}=2 / 132, \mathrm{p}<.005)$ and a significant Word Length by Exposure Time by VHF interaction $(F=2.70, d f=6 / 132, p<.025)$. The interaction of Exposure Duration by VHF was nonsignificant, as was the interaction of Exposure Duration by Word Length. Mean recognitions in the RVF were significantly greater than in the LVF in 11 of 12 orthogonal conditions of the experiment (all ps $<.05$ or less). Only the two-letter word length 100-msec exposure condition failed to show significant RVF superiority.

Table 1 shows that the main effects for word length and exposure time were regular decreases in overall recognition as word length increased and exposure durations decreased. It can also be seen that the Word Length by VHF interaction was based on a pattern of steadily declining LVF recognitions across increasing word lengths, as contrasted to the RVF pattern of essentially constant recognition levels at the two-, three-, and four-letter word lengths, with a significant decline occurring only for the five-letter words. The significant triple interaction would appear to occur mainly in the form of a consistent pattern of decreasing LVF recognitions with increasing word length at each exposure time, while such a pattern occurred only in the 25-msec condition for the RVF.

Table 2 shows the proportions of all recognitions that were RVF recognitions for each length-exposure time condition, as well as for each exposure time across lengths and each word length across exposure times. These RVF superiority magnitude measures show that four- and five-letter words produced identical RVF superiorities (.746), while three- and two-letter words produced substantially smaller RVF superiorities. Chi-square tests for differences between independent proportions showed that both four- and five-letter words yielded significantly higher RVF superiority than either of the two shorter word lengths (all four chi

Table 1

Mean RVF, LVF, and Combined VHF Recognition Scores for Twelve Word Length/Exposure Time Conditions

\begin{tabular}{|c|c|c|c|c|c|c|c|c|c|c|c|c|}
\hline \multirow{3}{*}{$\begin{array}{c}\text { Word } \\
\text { Length }\end{array}$} & \multicolumn{12}{|c|}{ Exposure Time } \\
\hline & \multicolumn{3}{|c|}{$25 \mathrm{Msec}$} & \multicolumn{3}{|c|}{$50 \mathrm{Msec}$} & \multicolumn{3}{|c|}{$100 \mathrm{Msec}$} & \multicolumn{3}{|c|}{ All Exposures } \\
\hline & RVF & LVF & Both & RVF & LVF & Both & RVF & LVF & Both & RVF & LVF & Both \\
\hline 2 & 8.75 & 4.25 & 6.50 & 13.58 & 9.25 & 11.42 & 17.67 & 13.75 & 15.71 & 13.33 & 9.08 & 11.21 \\
\hline 3 & 8.42 & 2.17 & 5.29 & 11.50 & 7.42 & 9.46 & 15.75 & 12.58 & 14.17 & 11.89 & 7.39 & 9.64 \\
\hline 4 & 5.83 & 1.75 & 3.79 & 14.58 & 5.50 & 10.04 & 18.50 & 7.33 & 12.92 & 12.97 & 4.86 & 8.92 \\
\hline 5 & 5.50 & 1.50 & 3.50 & 8.92 & 3.58 & 6.25 & 10.58 & 3.75 & 7.17 & 8.33 & 2.94 & 5.64 \\
\hline $\begin{array}{l}\text { All } \\
\text { Lengths }\end{array}$ & 7.13 & 2.42 & 4.77 & 12.15 & 6.44 & 9.29 & 15.63 & 9.35 & 12.49 & 11.63 & 6.07 & 8.85 \\
\hline
\end{tabular}


Table 2

Right Visual Field Recognition Superiority (Proportions) for Word Length, Exposure Time, and Word Length/ Exposure Time Conditions

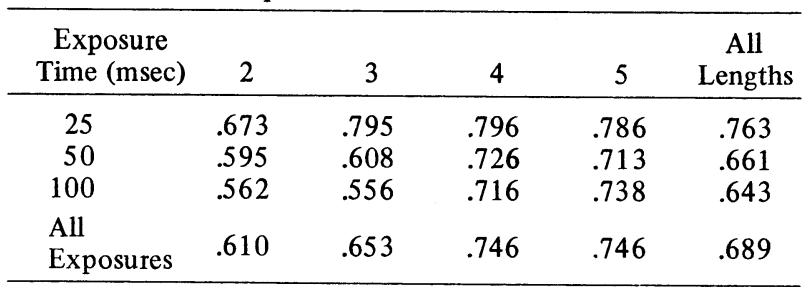

squares $=p<.01$ ), while RVF superiority did not differ between the two- and three-letter lengths or between the four- and five-letter lengths. Chi-square comparisons of the various exposure time conditions showed that 25-msec exposures produced significantly higher RVF superiority than either of the other exposures (both ps $<.01$ ), while the 50 - and 100-msec exposures did not differ in magnitudes of RVF superiority.

Finally, a measure of the "perceptual difficulty" of the word recognition conditions (ratio of the number of milliseconds available for viewing to the number of letters viewed) showed a substantial correlation (rho $=+.80, \mathrm{df}=10, \mathrm{p}<.01$ ) with magnitude of RVF superiority.

\section{DISCUSSION}

Increasing word length and decreasing exposure time produced regular decrements in overall recognition. However, susceptibility of the VHFs to recognition decrement with increasing length was asymmetric. The RVF recognition level was essentially constant for words of two-, three, and four letters, while the LVF showed substantially lowered recognition with each letter increment. This resulted in increasing RVF superiority as lengths increased from two to three to four letters. These findings are in very substantial agreement with Bouma's (1973) findings for unilaterally presented Dutch words. A minor difference is apparent, in that Bouma's recognition curves indicate virtually no recognition decrement in the RVF for any of the word lengths he studied at lateral eccentricities comparable to ours. Our results did show a substantial (significant by Tukey test) RVF recognition decrement as length increased from four- to five-letter words, and this reduction was greatest at the exposure time $(100 \mathrm{msec})$ Bouma employed. This discrepancy probably reflects the greater difficulty of bilateral over unilateral presentation (McKeever, 1971), with resultant RVF decrement occurring at a lesser word length in bilateral presentation.

The findings for word length are consistent with McKeever and Huling's (1971) assumption that RVF superiority would be greater for longer than for shorter words. They are also consistent with evidence that the LVF is more susceptible to lateral masking and metacontrast effects (Bouma, 1973; McKeever \& Suberi, 1974) and with evidence that metacontrast interference increases with increasing letter array size (Weisstein, 1966).

With respect to exposure time, the effect of shortening exposures was to produce comparable recognition decrements in both VHFs. This finding argues against any view that interhemispherically transferred neural stimulus traces undergo accelerating rates of degradation as stimulus intensity decreases. Nonetheless, the effect of comparable VHF recognition decrements, starting from a substantial RVF superiority even at the longest exposure, is inevitably to increase RVF recognition proportion scores as exposure times are reduced. In other words, the effect of shortening exposures does not interact with VHF recognitions, but it does "interact" with the ratio of the differences between VHF scores. These results also support the hypothesis (McKeever \& Huling, 1971; Hines, 1974) that shorter exposures are conducive to greater RVF superiority.

It is clear, then, that the magnitude of RVF recognition superiority depends largely on the stimulus length and exposure time studied. These variables together determine what we have called the "perceptual difficulty" of the task, with perceptual difficulty operationalized as the ratio of exposure time in milliseconds to the number of letters in the word. This measure rather analogous to the "rate of stimulus presentation" in dichotic listening procedures, a variable known to be critical in determining the extent of auditory asymmetry obtained in that task, had a substantial positive correlation $(+.80)$ with the magnitude of right-field superiority found for the lengthexposure time conditions of the experiment. In essence, the results show that substantial RVF superiority can be obtained with any of the word lengths studied if exposures of $25 \mathrm{msec}$ are employed, and with any of the exposures employed if the words are of four or five letters. It should be obvious that extreme difficulty, produced by very long word stimuli, very brief exposures, or some combination of these factors, would produce no VHF recognition asymmetries if the recognition threshold of the RVF was closely approached or surpassed.

Finally, this experiment supplies the first data with bilateral presentation and fixation control for word lengths other than four letters and shows that the RVF superiority obtained in previous studies (e.g., McKeever, 1971) was not specific to four-letter words. It should be noted that LVF superiority, predicted by the directional scanning hypothesis (Heron, 1957), did not obtain in any condition of the experiment, including those with the shortest words and longest exposures. The results are compatible with the lateral dominance model of visual half-field recognition differences.

\section{REFERENCES}

Bouma, H. Visual interference in the parafoveal recognition of initial and final letters of words. Vision Research, 1973, 13 , 767-782.

Heron, W. Perception as a function of retinal locus and attention. American Journal of Psychology, 1957, 70, 38-48.

Hines, D. Independent functioning of the two cerebral hemispheres for recognizing bilaterally presented tachistoscopic visual-half-field stimuli. Cortex, 1974, in press.

McKeever, W. F. Lateral word recognition: Effects of unilatera and bilateral presentation asynchrony of bilateral presentation, and forced order of report. Quarterly Journal of Experiment Psychology, 1971, 23, 410-416.

McKeever, W. F., \& Huling, M. D. Lateral dominance in tachistoscopic word recognition performances obtained with simultaneous bilateral input. Neuropsychologia, 1971, 9, 15-20.

McKeever, W. F., \& Suberi, M. Parallel but temporally displaced visual half-field metacontrast functions. Quarterly Journal of Experimental Psychology, 1974, 26, 258-265.

Mishkin, M., \& Forgays, D. B. Word recognition as a function of retinal locus. Journal of Experimental Psychology, 1952, 43, 43-48.

Olson, M. Laterality differences in tachistoscopic word recognition in normal and delayed readers in elementary school. Neuropsy chologia, 1973, 11, 343-350.

Teng, E. L., \& Sperry, R. W. Interhemispheric interaction during simultaneous bilateral presentation of letters or digits in commissurotignized patients. Neuropsychologia, 1973, 11, 131-140.

Thorndike, E. L., \& Lorge, I. The teachers book of 30,000 words. New York: Columbia University Press, 1944.

Weisstein, N. Backward masking and models of perceptual processing. Journal of Experimental Psychology, 1966, 72, 232-230.

\section{NOTE}

1. A few experiments with lateralized nonword stimuli (letter arrays) have been reported. None has studied the effects of both array size and exposure times.

(Received for publication July 8, 1974.) 